\title{
An approach to design a distributed knowledge-based platform for energy efficient cities
}

\author{
Pavel Vitliemov $^{1}$, Daniel Bratanov ${ }^{2}$, Milko Marinov $^{3}$ \\ 1 Department of Management and Business Development, University of Ruse, Bulgaria \\ 2 Department of Public Health and Social Activities, University of Ruse, Bulgaria \\ 3 Department of Computer Systems\&Technologies, University of Ruse, Bulgaria
}

\begin{abstract}
In this paper is presented an approach to design distributed knowledge-based software environment for energy efficient cities. All data gathered by the smart tools at domestic or public facilities can be accessed by the platform. Energy savings can be achieved as result from an optimized mix of both condition-based and preventive energy losses services that followed an online analysis of collected data. Algorithms and methods for an intelligent interpretation of the collected data can be developed within the platform in order to monitor the energy consumption process. Simulation of different scenarios forecasting the consumer's further behaviour in energy consumption will be the result of that intelligent interpretation.
\end{abstract}

\section{Introduction}

The Energy Efficiency Directive 2012/27/EU from 2012 to set a 20\% energy savings target by 2020 (when compared to the projected use of energy in 2020) is almost equivalent to close 400 power stations. $[1,2]$

In December 2018, the revised Energy Efficiency Directive entered into force (amending Directive EU (2018/2002) updating some specific provisions and introducing some new elements. Above all, it establishes a headline EU energy efficiency target for 2030 of at least $32.5 \%$ (compared to projections) with a clause for a possible upwards revision by 2023. $[3,4]$

Households account for $25-30 \%$ of European carbon emissions [5], with $80 \%+$ of household energy used on heating. Central to achieving energy conservation will be behaviour change in households, shifting towards more efficient domestic energy management [9]. This has been evidenced in a range of research on energy conservation $[6,8]$. Nowdays, it can be stated that a key barrier to household action on climate change is the sense that individuals cannot make a meaningful contribution to it, because is currently very difficult to measure the impact of an individual household, that make the sense that the issues are so large and is hard to personalize the impact an individual can have [10]. This makes the perspective for policy around Personal Carbon Allowances and emissions trading for households crucial from European Governments' perspective. [11]

The household action is currently difficult even if there was better information and can be stated that the household appliances and systems that use energy are rarely networked or automated intelligently. A major effort is required in order to making adjustments to settings to optimize environmental performance of different appliances and devices e.g. thermostat settings for heating, standby settings for appliances, temperature settings for washing machines and dryers etc.

It can be stated that holistic knowledge about energy efficiency potentials in cities is far from complete and nowdays a variety of individual strategies and approaches by different stakeholders are the basis in the strategic energy efficiency planning. An integrative approach to achieve the sustainable, energy efficient, smart city is a strategic issue by connecting scientific excellence and innovative enterprises in the energy sector. The pilot knowledge-based platforms can help all ambitious and well-organized cities to reduce energy use in Europe contributing to the EU's 20-20-20 targets ensuring following: $[6,9,10]$

- A real time Carbon footprint assessment, that depends on the sources of energy,

- A real time household energy efficiency rating that follows an analysis how the house is resulting in terms of heat loss and the efficiency of appliances,

- Recommendations for energy efficiency improvements based on the real time energy efficiency analysis,

- Recommendations for different usage profiles that match householders usage needs more energy efficiently, 
- Recommendations for forward settings based on online information about developing weather patterns and past usage patterns during these times.

Technological, behavioural and structural factors are integrated as different dimensions in energy efficiency improvements as these capabilities are embedded in improved practices, e.g. of building and using houses in a sustainable manner. [3]

Energy smart cities start with behaviour change of both individuals and organisations. Understanding how people make choices on their energy consumption - whether unconsciously or consciously will help for designing energy saving policies that will rely on behaviour as very much context-driven and subject to a multitude of situational and structural drivers. [4]

The main objective of presented approach within the paper is to contribute to above challenges with developing suitable tools to enable municipalities to improve their local and global performance at energy efficiency. All these techiques, methods and technologies can be implemented if "smart tools", that represent public and resident infrastructures equipped with up-to-date sensor technology will deliver real-time data from the energy consumption process and the energy manager will be introduced to the energy consumption and be aware of the actual condition. A cost-effective and rapid creation of both knowledge- and technology-based energy management services is made possible.

The Web-based platform that coordinate all forms of forward and backwards collaboration will supporting any activities along the value-adding chain based on smart tools that delivers real time data from the energy consumption process. Based on forecasts, errors or energy loses can be interpreted in real time by the energy manager, or energy consumer, thus minimizing the time to respond and the correction time, according to the appropriate energy consumption level based on the equal environmental conditions.

\section{Concept of proposed software platform architecture}

The concept of the work is based on the distribution of a set of data collectors with build-in web services. This data collector will be called for short - Jini (fig.1) [12]. The Jini is an electronic diary. Each jini will be able to collect and manage data broadcasted from different energy measurement sensors. The jinies have the intelligence to analyze the incoming data and connect with the data management center in the cases where there is a tendency for change in the situation. Thanks to the Jini, the municipality and the energy supply companies are able to surveillance, record and manage the energy consumption in the resident and public area continuously for years. The actual values for each energy sours together with the information collected for the environmental conditions are saved in the data collector in order to be used later on for statistical analyses. This allows the owners to predict and overcome eventual malfunctions of the energy system and prevent energy losses. The Jini is self-controlled. It is capable to control its own load and working regimes.

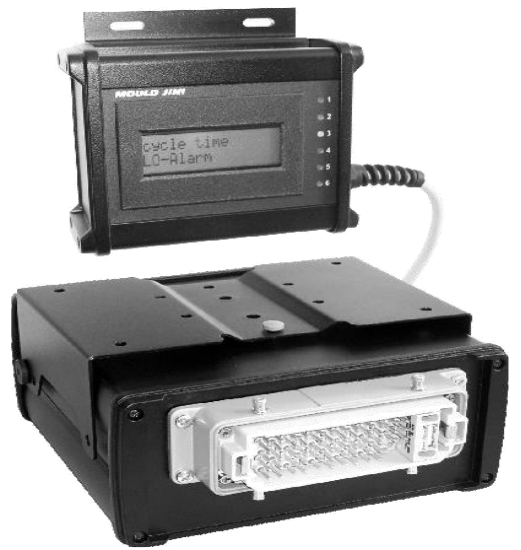

Figure 1. A view of a Jini manufactured by Feller Engineering GmbH, Germany [11]

As shown on fig.2 a network of Jinies can be linked via the internet to the energy management system [8]. The Jinies can be placed in very different locations and feed with variety of data. An example of architecture of a Jini installed in resident house is given in fig.3. 


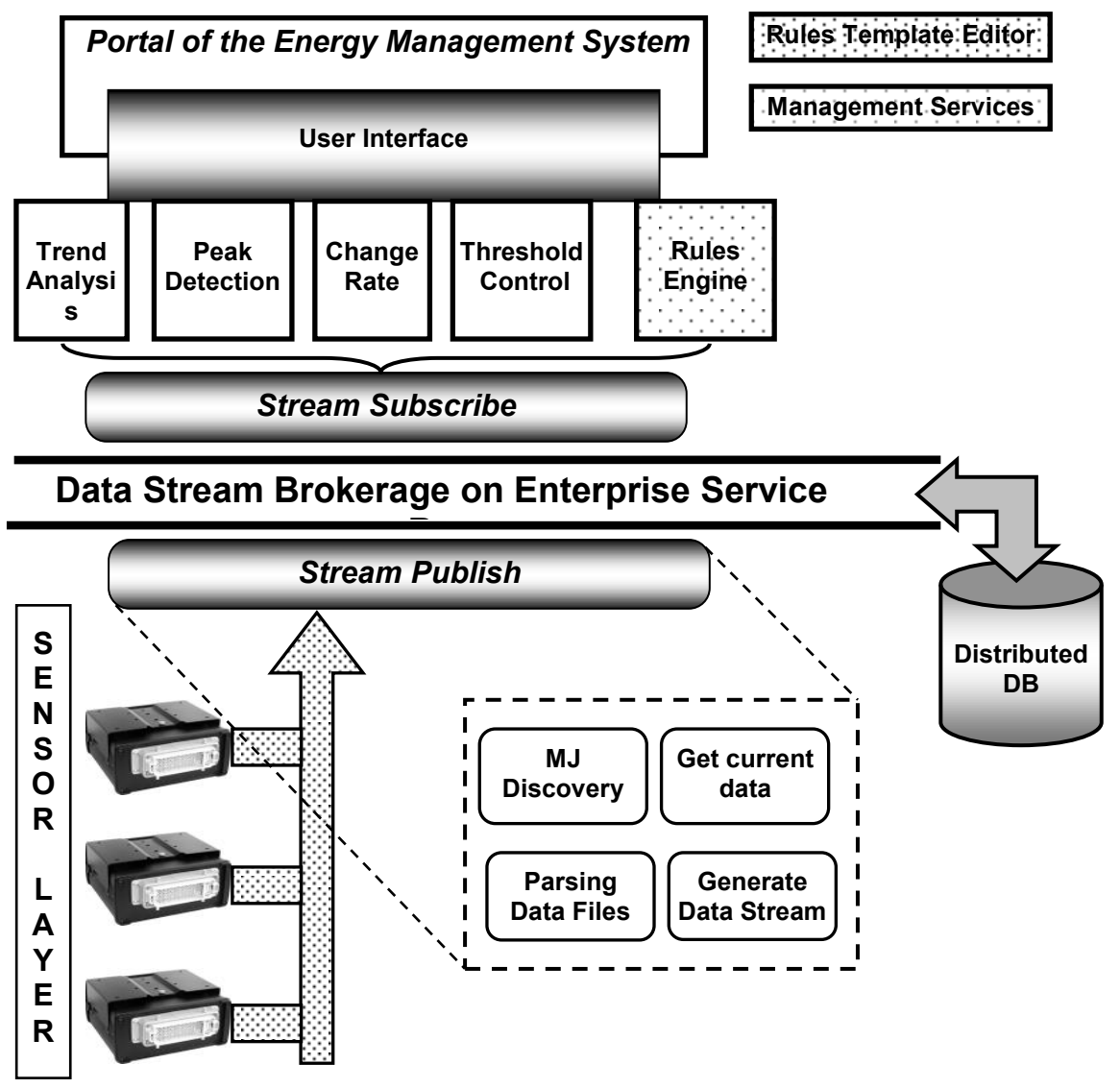

Figure 2. The architecture of Jini energy management software platform

The same architecture can be organized not only at domestic environment, but also to public buildings and even in the public transport. Many different systems are available on the market today that can measure and record the energy consumption. One of the basic disadvantages of those systems is in the lack of interpretation of the measured data. The idea that stands behind the architecture of Jini energy management software platform is that the collected data can be interpreted in different means by the ability of the end user to create different management profiles trough a rules engine. The rule engine provides the option for reconfiguration of the energy management system. This makes the energy management flexible and adaptable to the specific needs of the different users and energy plans available. A random setup of measurement units which data can be stored, analyzed and broadcasted by Jini is presented on fig. 4.

This feature provides a flexible way to access real time energy data gathered and an easy and flexible direct access to process data from any type of application for real time data processing. There is a data source (a publisher) that collects energy data and arrange them for a general provision, a broker that distributes the data on the bus, a subscriber that gets the data and put them within a XLM file to which an application can access. The ActiveMQ is used as broker activating the publish/subscribe services. ActiveMQ is an open source message broker that supports Java Message Service (JMS).

It is a standard Java API for creating, sending, receiving and reading messages. The communication between the broker and any application client is based on API (JMS interface). The logical and physical communication layer is represented from the Enterprise Service Bus component (ESB). ESB (ServiceMix/OpenESB) is a software component that lies between the energy applications and enables communication among them. 


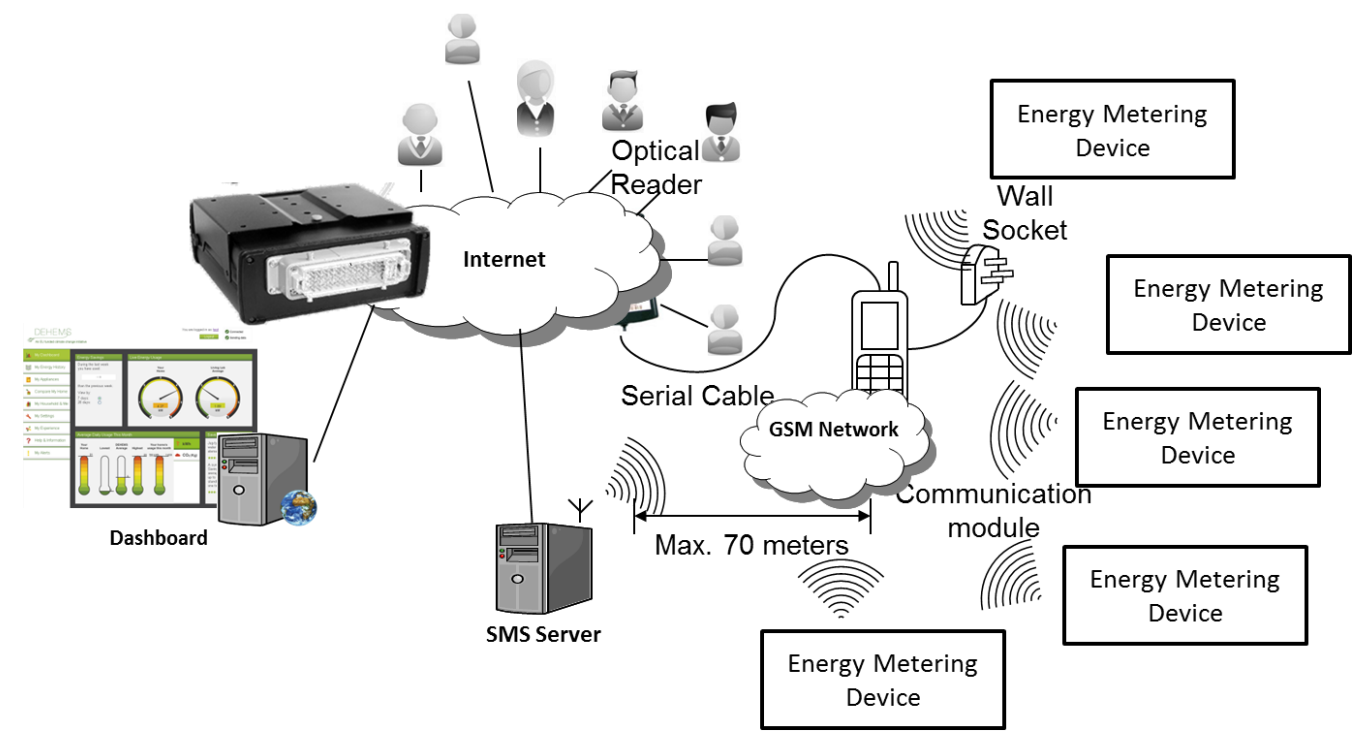

Figure 3. Jini installation architecture at domestic environment

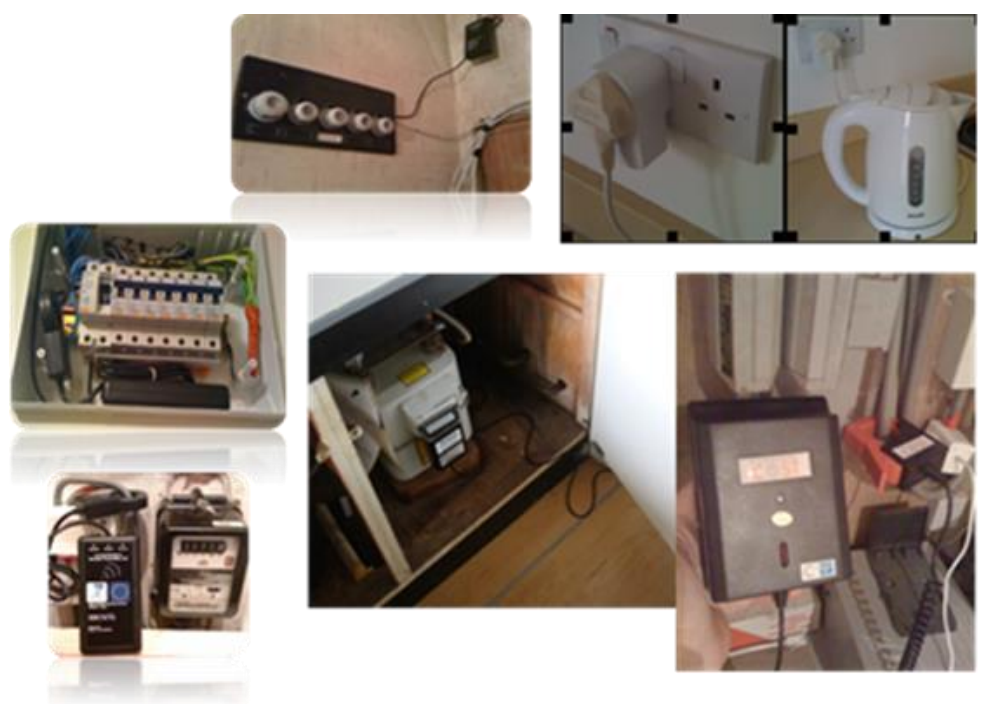

Figure 4. Different sensor setting for measurement of energy consumption

The data collected by the Jini from the different sensors can be managed in two different methods. In the first method the data is transferred from the Jini to the Portal of the energy management system. An example of Graphical User Interface GUI of such portal is shown on fig.5, where the user has the ability to monitor the current energy consumption via the average energy consumption for the region. 


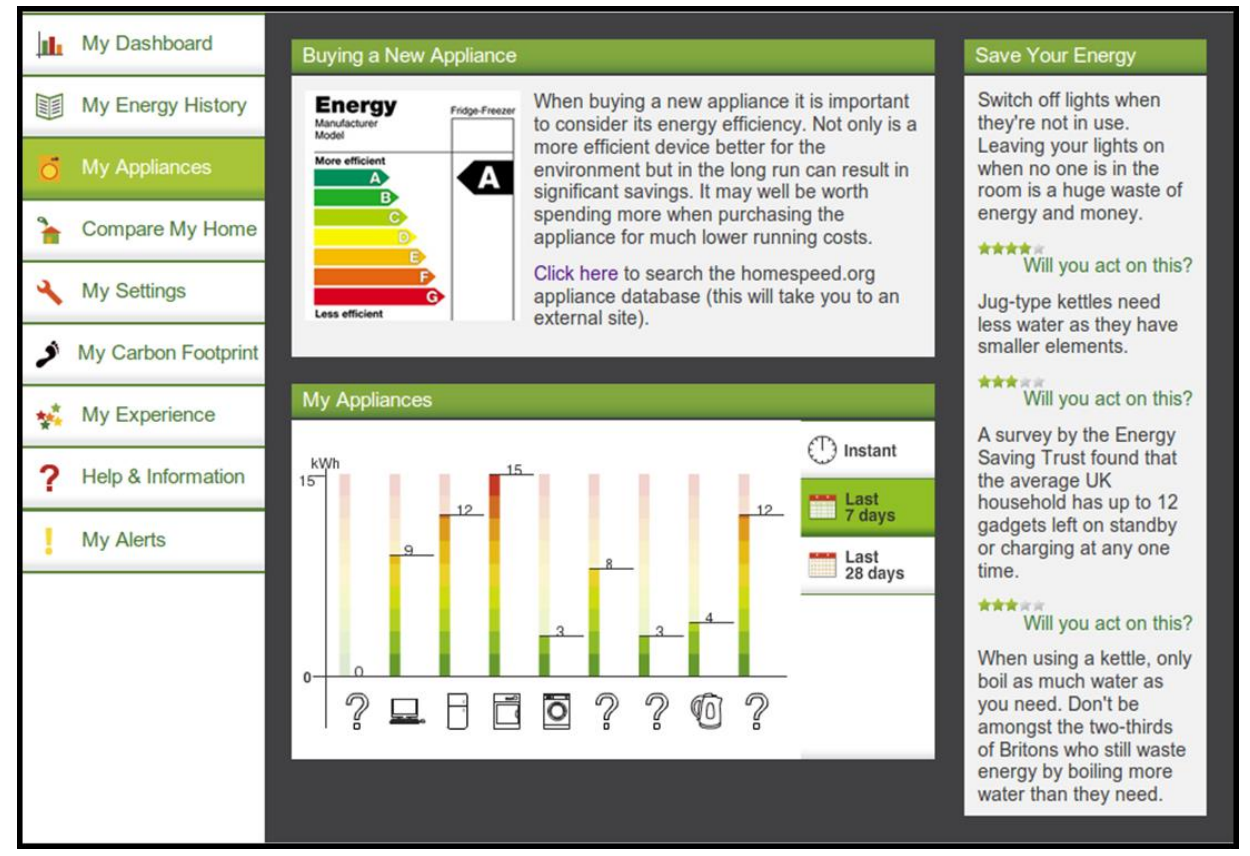

Figure 5. GUI of energy management portal

Each user of the portal has the ability to monitor his facilities. The monitoring process can be organized as overall monitoring or divided into monitoring of the different domestic appliances (fig.6) that are sending data to the Jini, respectively to the portal.

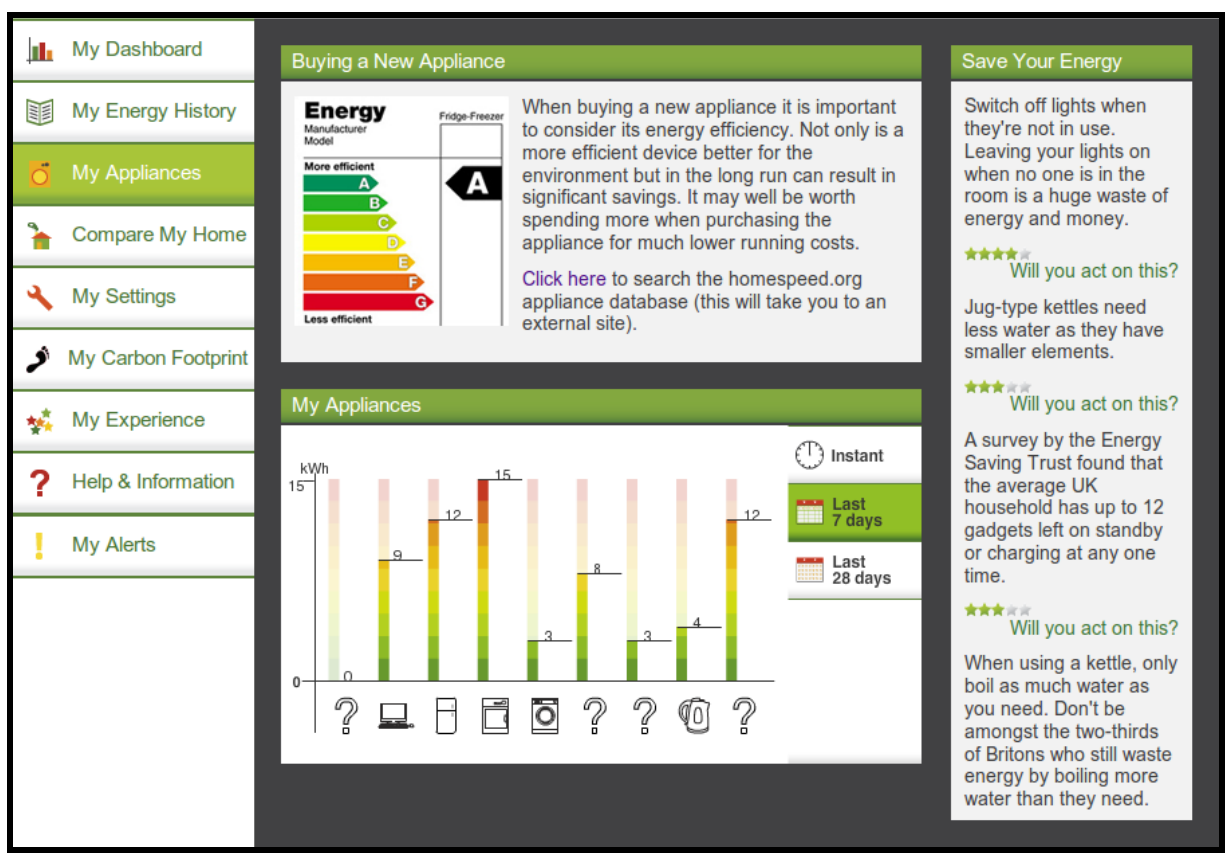

Figure 6. Labeling the domestic appliances to the management system 
The data collected in the Portal can be visualized in variety of ways, but this process still cannot be considered as energy management as it provides only statistical data. In order to transfer the surveillance and monitoring system for energy consumption into an energy management system an integration environment must be developed. The data interpretation boxes can be considered as the library containing algorithms and methods that can be used within different workflows. Basically these tools are used within a process that could be entirely or partially supported from the proposed platform facilities.

\section{Conclusions}

An approach to design a distributed knowledge-based software environment for energy efficient cities that will gather the data collected by the smart tools, data loggers equipped with up-to-date sensor technology delivering real-time data from the energy consumption process at domestic and public facilities is proposed in the paper.

It can be concluded that the proposed platform can move beyond current smart metering energy 'input' models that monitor the levels of energy being used by a household, towards energy 'performance' models that bringing together sensor data in areas such as household heat loss and appliance performance and all the data from energy meter systems and sensors e.g. for gas and electricity, can be analysed against energy intelligence on target efficiency, average efficiency rates and environmental conditions in order to provide practical information to the householder in a 'dashboard' that can be accessed online.

\section{References}

1. Energy Efficiency Directive (2018) (amending Directive EU (2018/2002);

2. EU Commission (2014), [1] Climate Change and Major Projects, Available at: https://ec.europa.eu/clima/sites/clima/files/docs/major_projects_en.pdf;

3. EU Commission (2014); Commission Delegated Regulation (EU) N:480/2014, Available at: https://eurlex.europa.eu/legal-content/EN/TXT/PDF/?uri=CELEX:32014R0480\&from=en;

4. EU Commission (2016), EU Reference Scenario, Energy, transport and GHG emissions Trends to 2050; Available at: https://ec.europa.eu/energy/sites/ener/files/documents/ref2016_report_final-web.pdf;

5. Climate Change Programme Review, Sustainable Development Commission, UK, 2005;

6. Jackson, T., (2005) Motivating Sustainable Consumption. A Report to the Sustainable Development Research Network;

7. Milko Marinov, Pavel Vitliemov, Elitsa Popova. Towards Big Data and Internet of Things as Key Aspects of Energy Efficiency.// TEM Journal, 2017, No 6(3), pp. 427-435, ISSN 2217-8309.

8. Mobilising individual behaviour change through community initiatives, Centre for Sustainable Energy, Community Development Exchange, 2007;

9. Kirova M.; Pr. Velikova (2016); Risk management method for small photovoltaic plants, Book Series: Proceedings of the 10th International Conference on Business Excellence in Energy, Climate Change and Sustainability Location: Bucharest, Romania Date: March 03, 2016;

10. Jackson, T., (2005) Motivating Sustainable Consumption. A Report to the Sustainable Development Research Network;

11. A Rough Guide to Individual Carbon Trading, Simon Roberts and Joshua Thumim, Centre for Sustainable Energy, Department for Environment and Rural Affairs, 2006;

12. FELLER ENG (2018) Operator manual. Feller Engineering GmbH, Germany. Available at http://www.fellereng.de/, accessed December 2018. 